\title{
Patient safety after implementation of a coproduced family centered communication programme: multicenter before and after intervention study
}

\author{
Alisa Khan, ${ }^{1,2}$ Nancy D Spector, ${ }^{3,4}$ Jennifer D Baird, ${ }^{5}$ Michele Ashland, ${ }^{6}$ Amy J Starmer, ${ }^{1,2}$ \\ Glenn Rosenbluth, ${ }^{7,8}$ Briana M Garcia, ${ }^{7,9}$ Katherine P Litterer, ${ }^{10}$ Jayne E Rogers, ${ }^{11}$ \\ Anuj K Dalal, ${ }^{1,12}$ Stuart Lipsitz, ${ }^{1,12}$ Catherine S Yoon, ${ }^{12}$ Katherine R Zigmont, ${ }^{12}$ Amy Guiot, ${ }^{13,14}$ \\ Jennifer K O'Toole, ${ }^{13,14}$ Aarti Patel, ${ }^{15,16}$ Zia Bismilla, ${ }^{17,18}$ Maitreya Coffey, ${ }^{17,18}$ Kate Langrish, ${ }^{19,20}$ \\ Rebecca L Blankenburg, ${ }^{21,22}$ Lauren A Destino, ${ }^{21,22}$ Jennifer L Everhart, ${ }^{21,22}$ Brian P Good, ${ }^{23,24}$ \\ Irene Kocolas, ${ }^{23,24}$ Rajendu Srivastava, ${ }^{23,24}$ Sharon Calaman, ${ }^{3,4}$ Sharon Cray, ${ }^{25}$ \\ Nicholas Kuzma, ${ }^{3,4}$ Kheyandra Lewis, ${ }^{3,4}$ E Douglas Thompson, ${ }^{3,4}$ Jennifer H Hepps, ${ }^{26,27}$ \\ Joseph O Lopreiato, ${ }^{26}$ Clifton E Yu, ${ }^{26,27}$ Helen Haskell, ${ }^{28}$ Elizabeth Kruvand, ${ }^{29,30}$ \\ Dale A Micalizzi, ${ }^{31}$ Wilma Alvarado-Little, ${ }^{32,32}$ Benard P Dreyer, ${ }^{34,35}$ H Shonna Yin, ${ }^{34,36}$ \\ Anupama Subramony, ${ }^{37,38}$ Shilpa J Patel, ${ }^{39,40}$ Theodore C Sectish,, ${ }^{1,2}$ Daniel C West, ${ }^{7,8}$ \\ Christopher P Landrigan, ${ }^{1,2,41}$ on behalf of the Patient and Family Centered I-PASS Study Group
}

For numbered affiliations see end of article.

Correspondence to: A Khan 21 Autumn Street, Room 200.2, Boston, MA 02115, USA alisa.khan@ childrens.harvard.edu (ORICD 0000-0002-1641-1061) Additional material is published online only. To view please visit the journal online.

Cite this as: $B M J$ 2018;363:k4764 http://dx.doi.org/10.1136/bmj.k4764

Accepted: 31 October 2018

\section{ABSTRACT}

OBJECTIVE

To determine whether medical errors, family experience, and communication processes improved after implementation of an intervention to standardize the structure of healthcare provider-family communication on family centered rounds.

DESIGN

Prospective, multicenter before and after intervention study.

SETTING

Pediatric inpatient units in seven North American hospitals, 17 December 2014 to 3 January 2017.

PARTICIPANTS

All patients admitted to study units (3106 admissions, 13171 patient days); 2148 parents or caregivers, 435 nurses, 203 medical students, and 586 residents.

INTERVENTION

Families, nurses, and physicians coproduced an intervention to standardize healthcare providerfamily communication on ward rounds ("family

\section{WHAT IS ALREADY KNOWN ON THIS TOPIC}

Interventions to improve communication between healthcare providers are associated with improved patient safety

However, effects on patient safety of interventions to improve communications between healthcare providers and patients/families have not been adequately studied in the inpatient setting

\section{WHAT THIS STUDY ADDS}

A team of physicians, nurses, and families coproduced an intervention to standardize rounds using high reliability structured communication that emphasized health literacy, family engagement, and bidirectional communication

Harmful errors decreased by $38 \%$ across seven North American academic hospitals after implementation of the intervention, although overall medical errors (harmful plus non-harmful errors) did not change

In addition, aspects of family experience and communication processes improved, without negative impacts on rounds duration or teaching on rounds centered rounds"), which included structured, high reliability communication on bedside rounds emphasizing health literacy, family engagement, and bidirectional communication; structured, written real-time summaries of rounds; a formal training programme for healthcare providers; and strategies to support teamwork, implementation, and process improvement.

\section{MAIN OUTCOME MEASURES}

Medical errors (primary outcome), including harmful errors (preventable adverse events) and nonharmful errors, modeled using Poisson regression and generalized estimating equations clustered by site; family experience; and communication processes (eg, family engagement on rounds). Errors were measured via an established systematic surveillance methodology including family safety reporting.

\section{RESULTS}

The overall rate of medical errors (per 1000 patient days) was unchanged (41.2 (95\% confidence interval 31.2 to 54.5 ) pre-intervention $v 35.8$ (26.9 to 47.7) post-intervention, $P=0.21$ ), but harmful errors (preventable adverse events) decreased by $37.9 \%$ (20.7 (15.3 to 28.1) v 12.9 (8.9 to 18.6 ), $\mathrm{P}=0.01$ ) post-intervention. Non-preventable adverse events also decreased (12.6 (8.9 to 17.9) v 5.2 (3.1 to 8.8), $\mathrm{P}=0.003$ ). Top box (eg, “excellent”) ratings for six of 25 components of family reported experience improved; none worsened. Family centered rounds occurred more frequently $(72.2 \%$ (53.5\% to $85.4 \%)$ $v 82.8 \%$ (64.9\% to $92.6 \%), \mathrm{P}=0.02)$. Family engagement $55.6 \%$ (32.9\% to $76.2 \%$ ) v $66.7 \%$ ( $43.0 \%$ to $84.1 \%$ ), $\mathrm{P}=0.04$ ) and nurse engagement (20.4\% (7.0\% to $46.6 \%) v 35.5 \%$ (17.0\% to $59.6 \%)$, $\mathrm{P}=0.03$ ) on rounds improved. Families expressing concerns at the start of rounds $(18.2 \%$ (5.6\% to $45.3 \%) v 37.7 \%$ (17.6\% to $63.3 \%), \mathrm{P}=0.03)$ and reading back plans $(4.7 \%(0.7 \%$ to $25.2 \%) \vee 26.5 \%$ (12.7\% to $7.3 \%), P=0.02)$ increased. Trainee teaching and the duration of rounds did not change significantly. 


\section{CONCLUSIONS}

Although overall errors were unchanged, harmful medical errors decreased and family experience and communication processes improved after implementation of a structured communication intervention for family centered rounds coproduced by families, nurses, and physicians. Family centered care processes may improve safety and quality of care without negatively impacting teaching or duration of rounds.

TRIAL REGISTRATION

ClinicalTrials.gov NCT02320175.

\section{Introduction}

Medical errors are a leading cause of death and harm in patients worldwide. ${ }^{1-4}$ Communication failures are in turn a leading root cause of sentinel events, the most serious harmful errors. ${ }^{5}$ Failures in many different communication processes in hospitals can lead to medical errors and patient harm. Interventions to reduce one type of communication failuremiscommunications during handoff of patient care responsibilities between healthcare providers at change of shift-have been associated with substantial improvements in patient safety. ${ }^{6-9}$ Little is known about whether efforts to reduce other communication failures-particularly miscommunications between healthcare providers, patients, and families-could result in improved patient safety.

Rounds (also known as "ward rounds") are an important daily communication process in hospitals that occur between physicians and patients and families, sometimes also involving nurses and other healthcare staff. The goal of rounds is to formulate and communicate a shared understanding of the day's care plan for inpatients. How rounds are structured, who participates, and how they participate varies by provider, specialty, hospital, and country. In some places, rounds occur in a conference room without the patient or family present. ${ }^{10}$ In other places, such as for decades now in the United Kingdom and more recently in North America, ${ }^{11} 12$ rounds occur at the bedside with the patient's family present ("family centered rounds"). Even in family centered rounds, structure, involvement of families, and the extent to which effective communication is achieved can vary widely. Given the frequency and variability of rounds, communication failures during rounds could potentially be an important, under-recognized source of medical errors that harm patients. However, despite the ubiquity of rounds, rigorous, multicenter studies of rounds and interventions to improve them are lacking.

To address this key evidence gap, we carried out a multicenter study in seven North American hospitals to determine whether patient safety, family experience, and communication processes would improve after the implementation of a programme to standardize communication with families on rounds. Families, nurses, and physicians coproduced the intervention, which emphasized structured verbal and written communication; health literacy, including use of plain language; family engagement; and bidirectional communication.

We hypothesized that improving communication between families, nurses, and physicians through this intervention would improve shared understanding about the patient among team members, thereby creating an extra safeguard to prevent medical errors. For example, if a family knows that a child routinely takes an antiepileptic, and a plan to continue this drug is not mentioned during family centered rounds, the family has the opportunity to intervene and prevent a potentially harmful omission. Additionally, we postulated that improving communication with families might improve their hospital experience. We measured communication processes both to determine the level of adherence to various components of the intervention and to examine whether any measured changes in key outcomes were accompanied by particular changes in communication processes.

\section{Methods \\ Study design}

We conducted an intervention study on pediatric units in seven North American hospitals from December 2014 to January 2017. We assigned each site to one of three staggered waves of implementation and data collection. At each site, we measured care processes and outcomes three months pre-intervention, followed by a nine month intervention implementation and iterative refinement period. We then collected three months of post-intervention data at each site, matched by time of year with pre-intervention data collection to control for confounding owing to seasonality and level of resident-physician experience.

\section{Study team}

Our study group included more than 100 collaborating parents, nurses, and physicians, including health services researchers, medical educators, hospitalists, communication experts, and health literacy experts. Parents and nurses were integrated into every aspect of the study, from development and refinement of the intervention to creation of data instruments.

\section{Participants}

All patients, resident physicians, nurses, and medical students on the study units, as well as English, Arabic, Chinese, Russian, and Spanish speaking parents, guardians, or care givers of patients aged less than 18 years were eligible to participate in the study. The languages we included represented those most commonly spoken across study sites. We obtained verbal consent from parents and medical students and written informed consent from resident physicians and nurses to conduct interviews and surveys. Attending physicians participated in the intervention but were not asked to complete surveys so did not need to provide consent. We obtained waivers of consent to review patient charts. Participants received small incentives (eg, snacks). 


\section{Participating sites}

We collected data from inpatient pediatric medical (non-intensive care) units at one Canadian and six US teaching hospitals, ranging in size from 189 to 540 beds. Participating pediatric residency programs ranged in size from 35 to 190 residents. Study units at each hospital included general pediatrics patients; some also included specialty care patients (pulmonary/ endocrinology, hematology/oncology, and surgical; three sites) or complex care patients (one site). Units had an average daily patient number of 10 to 30 patients. All sites were acute care hospitals. Three sites were freestanding children's hospitals, three were pediatric hospitals within larger systems, and one was a pediatric unit within an adult hospital. Over half of the hospitals had double (non-private) rooms.

\section{Rounding practices at baseline}

Before the intervention, most sites did not have a formal structure for rounds, and who was present for rounds varied by site. Attending physicians, senior residents, interns, and medical students were always present on rounds, though their specific roles on rounds varied. At most sites, senior residents directed rounds and attending physicians played a supportive role, although at some sites attending physicians directly led rounds. The frequency of bedside nurse presence on rounds in particular varied by site, with only two sites reporting that nurses were present at least $80 \%$ of the time. The role of the bedside nurse on rounds also varied. Fellows, social workers, pharmacists, care coordinators or case managers, and child life therapists were also routinely present for rounds at some sites. Rounds typically lasted two to three hours. Two sites did not conduct rounds at the bedside but rather in a conference room (ie, formulated plans in a conference room without input from patients or their families). Five sites had recently begun bedside rounds (within the past 2-7 years), though the involvement of patients and families on rounds varied.

For sites that practiced bedside rounds, the extent to which rounds actually occurred at the bedside before the intervention varied by volume and acuity of service, day of week (weekend versus weekday), patient characteristics (eg, whether the family spoke English or whether there were active social problems), hospital unit, and provider preference. Health literacy principles were not typically followed, medical jargon was frequently used, and presentations were often directed at the senior resident or attending physician rather than the patient or family. Written updates were not typically provided to families during rounds. The family's role on rounds was typically passive-restricted to listening to the presentation and occasionally providing some clarifying information or asking questions at the end.

\section{Intervention development}

A team of parents, nurses, and physicians, including health services researchers, medical educators, hospitalists, communication experts, and health literacy experts, coproduced the interventionPatient and Family Centered I-PASS. Our overarching goal was to redesign rounds to make them more

Box 1: Patient and Family Centered I-PASS intervention

Structured verbal communication during rounds

- Structured communication framework based on I-PASS mnemonic

- I-Illness severity (family reports if child was better, worse, or same); nurse input solicited

- P-Patient summary (brief summary of patient presentation, overnight events, plan)

- A-Action list (to-dos for day)

- S-Situation awareness and contingency planning (what family and staff should look out for and what might happen)

- S-Synthesis by receiver (family reads back key points of plan for day, prompted by presenter, supported by nurse as needed)

- Emphasized:

- Family engagement (eg, family speaks first, shares questions and concerns first on rounds)

- Health literacy (using plain language, eg, fever, not febrile)

- Bidirectional communication (ie, synthesis by receiver)

- Interprofessional and nurse engagement (nurses speak early on rounds, nurse-physician huddles)

Structured written communication during rounds

- Rounds report

- Daily written summary of rounds for family organized in I-PASS format

- Completed in real time on whiteboard (five sites) or paper (two sites)

Training and learning

- Interactive learner specific workshops for faculty (one hour), residents (2-3 hours), and nurses (15 minutes) reinforced by:

- Simulation and role play exercises

- Computer based video modules

- Family and patient orientation and rounds brochure

Strategies to support teamwork and implementation

- Mid-shift afternoon and overnight nurse-physician huddles to address patient care issues and family concerns

- Structured weekly observations, assessment, and feedback by trained observers (physician faculty and nurses) to improve team performance on rounds

- Sustainability campaign (development of a logo, posters, and other materials to promote the programme and provide visual reminders for the team) 
family centered and to improve the effectiveness of communication using structured methods of high reliability communication. We did so through an iterative, consensus building process through a series of teleconferences and in-person meetings informed by a review of the literature and our previous research. $^{813}$

\section{Intervention}

The intervention consisted of: (1) a structured high reliability communication framework for rounds bolstered by health literacy (including using plain language, eg, saying "fever" instead of "febrile"), ${ }^{14}$ family engagement, and bidirectional communication principles, organized around the I-PASS mnemonic (Illness severity, Patient summary, Action list, Situation awareness and contingency planning, Synthesis by receiver), adapted for this study; (2) a "rounds report," a written (whiteboard or paper) daily summary of rounds for families provided in I-PASS format and completed in realtime; (3) a rounds training and learning programme for interprofessional team members; and (4) the introduction of several process changes to support teamwork and implementation of the programme, including mid-shift nurse-physician huddles to discuss patient care issues or family concerns, structured observations of bedside rounds with feedback to improve team performance on rounds, and a sustainability campaign (box 1).

The structured communication framework we developed in the I-PASS Resident Handoff Study ${ }^{8}$ required adaptation for use in the current study for two reasons: this previous study focused exclusively on communication during handoffs, not other types of communication during hospital admission, such as on rounds; and it included resident physicians only, not nurses or patients and families. Therefore, the use of the I-PASS format needed to be modified to be appropriate both for rounds and for a wider group of people. In the current study, we sought to have the family report illness severity at the beginning of rounds, with input from the bedside nurse. Resident physicians then reported the patient summary, action items, and situation awareness and contingency planning on rounds using plain language. The synthesis was ideally provided by the family, again with support from the bedside nurse as needed (box 1). These adaptations to rounds were made with extensive input from family members, nurses, and physicians from across participating centers. Box 2 provides details of how the implementation was rolled out.

Box 2: Details about Patient and Family Centered I-PASS programme. Based on TIDieR (Template for Intervention Description and Replication)

\section{Name}

1.

- Patient and Family Centered I-PASS

Why

2.

- To improve and standardize communication on rounds by emphasizing health literacy, family engagement, and bidirectional communication

What

3.

Materials

- Family brochure: orientation to team member (including family) roles and responsibilities on rounds

- Rounds report: daily written real time summary of rounds for family organized in I-PASS format

- Nurse training module (slide deck, voiceover module): nurse and family engagement strategies, nursing role on rounds, health literacy, I-PASS format

- Medical student module (slide deck, role play exercises): family engagement strategies, medical student role, health literacy, I-PASS format

- Resident training module (slide deck, role play exercises): family engagement strategies, resident role, health literacy, I-PASS format

- Attending training module (slide deck, role play exercises): family engagement strategies, team member roles, health literacy, teaching strategies, I-PASS format

- Implementation guide: 62 page "how-to" guide for intervention implementation, designed for site leaders responsible for implementing intervention

- Observation tools (including core items and modules on activating and engaging the family and interprofessional team, patient centered conversation and written information, use of structured communication techniques, and teaching)

- Campaign materials to encourage adoption of the intervention (eg, logo, posters)

4.

Procedures:

- Patient/family orientation at admission (facilitated by family brochure) 
- Changes to verbal communication on rounds (I-PASS mnemonic, families speak first, families engage in bidirectional communication-eg, read back plan; providers use universal health literacy precautions; nurses speak early on rounds)

- Completion of rounds report on rounds (completed on paper at two sites; on whiteboard at five sites)

- Mid-shift nurse-physician huddles (daytime and overnight to address patient care issues and family concerns)

- Structured weekly observations with assessment and feedback by trained observers (physician faculty and nurses) to reinforce programme, and iteratively improve performance on rounds

\section{Who provided}

5.

- Physician leads: pediatric hospitalists who had undergone intervention training

- Nurse leads: bedside or nurse educators or nurse leaders who had undergone intervention training

- Family leads: family partners who had undergone intervention training, helped train residents at some sites

\section{How}

6.

- Training conducted in-person, face-to-face at resident orientation or staff meeting (eg, faculty or nurses) or individual meetings

- Some nurses completed online training, independently (ie, nurse voiceover slide deck)

- Reinforcement and feedback provided one-on-one, in person

- In person meetings and teleconferences (over phone and internet) for physician, nurse, family leads to oversee study across sites

\section{Where}

7.

- Families: at admission, on study unit

- Nurses: staff meeting on study unit or independent voiceover module at location of their choice

- Residents: training programme retreat/orientation, or during teaching conference

- Attendings: staff meeting on unit, small group or individual meetings, or teleconference

- Medical students: at orientation, on study unit

\section{When and how much}

8.

- Intervention (trainings and changes to rounds procedures) implemented from March 2015 to January 2017

- Family orientations facilitated by brochure: at every admission

- Nurse training (15 minutes): 680 nurses trained over 42 sessions

- Medical student training (1 hour): 506 medical students trained over 63 sessions

- Resident training (2-3 hours each): 515 residents trained over 34 sessions

- Attending training (1 hour): 182 faculty trained over 26 sessions

\section{Tailoring}

9.

- Training modules were streamlined to meet local site scheduling constraints, For example, time allotted by individual residency training programs for the resident training module at resident orientation varied between two hours at some sites and three hours at others

\section{Modifications}

10.

- Intervention was iteratively refined during the intervention period based on participant feedback, before post-intervention data collection-for example, synthesis by receiver and the format of the patient summary were refined

How well

11.

Planned:

- Research assistant live observations of rounds

- Post hoc analyses of research assistant recordings of rounds observations

- Quality improvement observations by faculty and nurses of team performance

12

Actual:

- Research assistant live observations of rounds (see fig 2)

- Post hoc analyses of research assistant recordings of rounds observations (see fig 2)

- Quality improvement observations by faculty and nurses of team performance-varied from $35 \%$ adherence for nurse participation on rounds to $100 \%$ adherence for families speaking first on rounds 


\section{Study outcomes}

Our primary outcome was the rate of medical errors, including harmful errors (preventable adverse events) and non-harmful errors. Additional measures of interest were rates of non-preventable adverse events, family experience, and communication processes.

\section{Medical errors and adverse events}

We measured medical errors and adverse events per 1000 patient days using an established systematic safety surveillance method. ${ }^{6815-18}$ A medical error was defined as a failure in care process (eg, administering penicillin to a patient with a known penicillin allergy). Medical errors included those that led to harm (harmful error; also known as preventable adverse event) or no harm (non-harmful error) (see supplementary figure 1). An adverse event was defined as a harm to a patient related to medical care (eg, anaphylaxis due to penicillin). Adverse events included those that are due to an error (eg, anaphylaxis due to penicillin in a patient with a known penicillin allergy) (preventable adverse event, also known as harmful error) and not due to an error (eg, anaphylaxis due to penicillin in a patient with no previously known drug allergies) (nonpreventable adverse event).

After completion of standardized training, every weekday (weekend data were collected on Monday), site research clinicians collected data on suspected medical errors and adverse events using a well established surveillance method. ${ }^{6} 8$ 15-18 This method entailed reviewing medical records of all patients admitted to hospital on each study unit, post-shift provider (eg, physician and nurse) surveys, and hospital incident reports. In addition, to solicit patient and family input in the error surveillance process, our group modified this standard surveillance process to include family safety interviews of parents, guardians, or caregivers of eligible in-patients about suspected safety events. ${ }^{19}$ For longer stay patients, we conducted family safety interviews before discharge and every seven days.

Two trained physician reviewers blinded to preintervention and post-intervention status categorized all suspected medical errors and adverse events (gathered through the standard surveillance method or family safety interviews) as either adverse events, non-harmful errors, or exclusions (pre-consensus agreement $=68.9 \% ; \kappa=0.53,95 \%$ confidence interval 0.48 to 0.58 ). Physician-reviewer pairs subcategorized adverse events as preventable or non-preventable (preconsensus agreement $=83.5 \%$; $\kappa=0.64,0.54$ to 0.74 ). If evidence suggested that an error had occurred, the adverse event was deemed preventable, whereas if evidence of an error was not found, the adverse event was deemed non-preventable. Physician-reviewer pairs then reconciled discordant categorizations through consensus.

\section{Family experience}

We measured family experience using a survey administered before discharge to two randomly selected families each week per site. We developed, cognitively tested, and piloted the survey at a nonintervention site $(\mathrm{BCH})$ and translated it into Arabic, Chinese, Russian, and Spanish. This 10-15 minute survey had a Flesch-Kincaid ${ }^{20}$ grade level of 5.9 (ie, a nearly sixth grade reading level) and was administered by site research assistants verbally, electronically, or on paper. The survey asked parents to rate experience during and after rounds, with written communication, with physicians and nurses, and during the overall hospital stay.

\section{Communication processes}

To measure communication processes, research assistants conducted one hour weekly in-person observation sessions of rounds per site, simultaneously completing a real time assessment tool for each patient and audio recording rounds. A median of 3 (interquartile range 2-5) patients per session were observed. Using an iterative process, including pilot testing, we developed structured observation tools to measure the quality of communication on rounds, family and nurse engagement, and the duration of rounds. Site research clinicians blinded to preintervention versus post-intervention status then conducted post hoc analyses of a subset (two patients each week per site) of rounds audio recordings using a structured assessment tool to measure adherence by the team members on rounds to evidence based communication processes (eg, using plain language effectively during rounds).

\section{Other variables of interest}

We collected self reported parent and provider sociodemographic data from surveys, and patient demographic data from hospital administrative data (table 1). Variables included participants' age, sex, race; patient insurance and complex chronic conditions (marker of medical complexity on basis of international classification of diseases, clinical modification, ninth and 10 th revisions) ${ }^{2122}$; parent or caregiver relationship to patient, language, education, and income; and provider position or year of training.

\section{Statistical analyses}

To compare error and adverse event rates (per 1000 patient days) pre-intervention versus post-intervention, we used Poisson regression estimated via generalized estimating equations (GEE) to account for clustering of patients within site; the GEE estimation procedure allows for overdispersion. When initially designing the study, we did not plan to include incidents captured solely through family reporting (family safety interviews) in our primary outcome measure because this method had not been adequately tested. However, once we had determined that incidents captured through family safety interviews were valid and that these reports generated safety data that were not captured through the standard surveillance method, ${ }^{19}$ we elected to modify our design to include data derived from both family safety interviews and standard 


\begin{tabular}{|c|c|c|c|}
\hline Characteristics & Pre-intervention & Post-intervention & $P$ valuet \\
\hline Patients $¥$ & $n=1574$ & $n=1532$ & \\
\hline Mean (SE) age (years) & $6.9(1.7)$ & $7.3(1.7)$ & 0.65 \\
\hline \multicolumn{4}{|l|}{ Sex: } \\
\hline Female & $767(49.7)$ & $765(51.3)$ & \multirow[t]{2}{*}{0.94} \\
\hline Male & $775(50.3)$ & $727(48.7)$ & \\
\hline \multicolumn{4}{|l|}{ Race: } \\
\hline Asian & $74(5.4)$ & $58(4.5)$ & \multirow[t]{4}{*}{0.38} \\
\hline Black & $266(19.6)$ & $221(17.3)$ & \\
\hline White & $708(52.1)$ & $600(46.9)$ & \\
\hline Other & $312(22.9)$ & $400(31.3)$ & \\
\hline \multicolumn{4}{|l|}{ Insurance: } \\
\hline Government/public & $1051(68.3)$ & $1072(71.7)$ & \multirow[t]{2}{*}{0.58} \\
\hline Non-government/private & $487(31.7)$ & $423(28.3)$ & \\
\hline \multicolumn{4}{|c|}{ Complex chronic conditions count§: } \\
\hline 0 & $1171(74.4)$ & $1084(70.8)$ & \multirow[t]{3}{*}{0.74} \\
\hline 1 & $268(17.0)$ & $334(21.8)$ & \\
\hline$\geq 2$ & $135(8.6)$ & $114(7.4)$ & \\
\hline Mean (SE) length of stay (days) & $5.6(1.7)$ & $5.1(1.3)$ & 0.70 \\
\hline Parentsף & $n=947$ & $\mathrm{n}=890$ & \\
\hline Mean (SE) age (years) & $36.0(1.2)$ & $36.3(1.2)$ & 0.50 \\
\hline \multicolumn{4}{|l|}{ Sex: } \\
\hline Female & $731(81.7)$ & $648(79.9)$ & \multirow[t]{2}{*}{0.51} \\
\hline Male & $164(18.3)$ & $163(20.1)$ & \\
\hline \multicolumn{4}{|l|}{ Race/ethnicity: } \\
\hline Hispanic or Latino & $193(21.5)$ & $181(22.4)$ & \multirow[t]{5}{*}{0.82} \\
\hline Asian, non-Hispanic & $62(6.9)$ & $50(6.2)$ & \\
\hline Black, non-Hispanic & $158(17.6)$ & $122(15.1)$ & \\
\hline White, non-Hispanic & $424(47.2)$ & $376(46.6)$ & \\
\hline Other race, non-Hispanic & $62(6.9)$ & $78(9.7)$ & \\
\hline \multicolumn{4}{|l|}{ Relationship to patient: } \\
\hline Parent & $853(95.5)$ & $765(95.4)$ & \multirow[t]{4}{*}{0.84} \\
\hline Grandparent & $21(2.4)$ & $20(2.5)$ & \\
\hline Guardian & $4(0.5)$ & $7(0.9)$ & \\
\hline Other & $15(1.7)$ & $10(1.3)$ & \\
\hline \multicolumn{4}{|c|}{ Language most comfortable speaking with providers: } \\
\hline English & $804(92.1)$ & $718(90.1)$ & 0.74 \\
\hline Spanish & $47(5.4)$ & $58(7.3)$ & \\
\hline Other & $22(2.5)$ & $21(2.6)$ & \\
\hline How well parent speaks English & & & \\
\hline Not at all & $17(1.9)$ & $26(3.2)$ & 0.50 \\
\hline Not well & $20(2.2)$ & $32(4.0)$ & \\
\hline Well & $66(7.4)$ & $62(7.7)$ & \\
\hline Very well & $788(88.4)$ & $690(85.2)$ & \\
\hline Satisfaction with ability to read & & & \\
\hline Very dissatisfied & $30(3.4)$ & $39(4.9)$ & 0.30 \\
\hline Somewhat dissatisfied & $8(0.9)$ & $19(2.4)$ & \\
\hline Satisfied & $84(9.5)$ & $41(5.2)$ & \\
\hline Somewhat satisfied & $22(2.5)$ & $18(2.3)$ & \\
\hline Very satisfied & $738(83.7)$ & $679(85.3)$ & \\
\hline Education: & & & \\
\hline Less than high school & $30(3.4)$ & $28(3.5)$ & 0.18 \\
\hline Some or all of high school & $301(34.2)$ & $231(29.0)$ & \\
\hline Some college or more & $549(62.4)$ & $538(67.5)$ & \\
\hline Annual household income (\$): & & & \\
\hline$<14999$ & $88(15.3)$ & $127(20.6)$ & 0.17 \\
\hline $15000-49999$ & $184(32.0)$ & $192(31.1)$ & \\
\hline $50000-99999$ & $154(26.8)$ & $155(25.1)$ & \\
\hline$\geq 100000$ & $149(25.9)$ & $143(23.2)$ & \\
\hline Physicians & $n=343$ & $n=252$ & \\
\hline Mean (SE) age (years) & $28.5(0.3)$ & $28.2(0.3)$ & 0.33 \\
\hline Sex: & & & \\
\hline Female & $236(69.0)$ & $167(67.1)$ & 0.52 \\
\hline Male & $106(31.0)$ & $82(32.9)$ & \\
\hline Race/ethnicity: & & & \\
\hline
\end{tabular}




\begin{tabular}{|c|c|c|c|}
\hline Characteristics & Pre-intervention & Post-intervention & P valuet \\
\hline Hispanic or Latino & $23(7.0)$ & $9(3.6)$ & \multirow{5}{*}{0.74} \\
\hline Asian, non-Hispanic & $60(18.1)$ & $39(15.7)$ & \\
\hline Black, non-Hispanic & $11(3.3)$ & $11(4.4)$ & \\
\hline White, non-Hispanic & $226(68.3)$ & $176(71.0)$ & \\
\hline Other race, non-Hispanic & $11(3.3)$ & $13(5.2)$ & \\
\hline \multicolumn{4}{|l|}{ Training level: } \\
\hline Postgraduate year 1 & $163(47.5)$ & $101(40.1)$ & \multirow{5}{*}{0.11} \\
\hline Postgraduate year 2 & $64(18.7)$ & $31(12.3)$ & \\
\hline Postgraduate year 3 & $68(19.8)$ & $42(16.7)$ & \\
\hline Medical student & $44(12.8)$ & $77(30.6)$ & \\
\hline Other & $4(1.2)$ & $1(0.4)$ & \\
\hline Nursesף & $\mathrm{n}=191$ & $\mathrm{n}=139$ & \\
\hline Mean (SE) age (years) & $34.4(0.8)$ & $35.5(0.9)$ & 0.36 \\
\hline \multicolumn{4}{|l|}{ Sex: } \\
\hline Female & $171(91.4)$ & $124(89.2)$ & \multirow{2}{*}{0.43} \\
\hline Male & $16(8.6)$ & $15(10.8)$ & \\
\hline \multicolumn{4}{|l|}{ Race/ethnicity: } \\
\hline Hispanic or Latino & $13(7.1)$ & $5(3.8)$ & \multirow{5}{*}{0.47} \\
\hline Asian, non-Hispanic & $26(14.1)$ & $23(17.3)$ & \\
\hline Black, non-Hispanic & $5(2.7)$ & $7(5.3)$ & \\
\hline White, non-Hispanic & $129(70.1)$ & $96(72.2)$ & \\
\hline Other race, non-Hispanic & $11(6.0)$ & $2(1.5)$ & \\
\hline \multicolumn{4}{|l|}{ Staff nurse level: } \\
\hline 1 & $61(31.9)$ & $53(38.1)$ & \multirow{3}{*}{0.71} \\
\hline 2 & $81(42.4)$ & $50(36.0)$ & \\
\hline 3 & $36(18.9)$ & $28(20.1)$ & \\
\hline Advanced practice & $9(4.7)$ & $5(3.6)$ & \\
\hline Other & $4(2.1)$ & $3(2.2)$ & \\
\hline \multicolumn{4}{|c|}{$\begin{array}{l}\text { *All percentages reflect non-missing data. Missing data ranged from } 2.0 \% \text { to } 9.7 \% \text {, except for patient race (15.0\%) and annual household income } \\
\text { (35.1\%). Missingness was similar in pre-intervention and post-intervention cohorts. } \\
\text { tP values for variables with more than } 5 \% \text { missing data were calculated with multiple (300) imputations. } \\
\text { fPatient characteristics derived from hospital administrative data. } \\
\text { \$The complex comorbidities conditions system uses ICD-9-CM (international classification of diseases, ninth revision, clinical modification) codes to } \\
\text { capture children with complex medical conditions, namely those with medical conditions expected to last } 12 \text { months or more that involve several different } \\
\text { organ systems or one organ system severely enough to require specialty pediatric care and hospitalization in a tertiary care center. }{ }^{2122} \\
\text { ๆCharacteristics derived from self reported survey data. }\end{array}$} \\
\hline
\end{tabular}

surveillance in the primary outcome measure. As a sensitivity analysis, we ran a second set of Poisson regression models excluding those medical errors and adverse events captured solely through family safety interviews, consistent with our original analysis plan.

On the basis of preliminary data, we anticipated that we needed to accrue a minimal sample size of 2430 patient days of data per period, to have $80 \%$ power to detect a $20 \%$ reduction in medical errors, assuming an $\alpha=0.05$ type I error rate. Across multiple sites, we anticipated accruing several times this many patients.

For experience and communication process data, we compared per cent top box ratings (choosing the top most response on a scale; eg, "excellent" or 5 out of 5) pre-intervention versus post-intervention using a GEE $\chi^{2}$ test for binary outcomes, clustered by site.

We analyzed variables that were potential confounders, including patient, parent, and provider characteristics, in the pre-intervention versus postintervention periods to ensure no variables differed statistically significantly and required further adjustment in analyses. For variables with more than $5 \%$ missing data, we used multiple imputation appropriate for missing data in clustered studies. ${ }^{23-25}$ Distributions of possible confounders were comparable between pre-intervention and post-intervention periods. For simplicity, we present unadjusted results, accounting for clustering by site.
For our two facet primary outcome (errors, which includes harmful and non-harmful errors), we applied a Bonferroni correction, considering $\mathrm{P}<0.025$ to be significant. For secondary analyses, we considered $\mathrm{P}<0.05$ to be significant. We used REDCap ${ }^{26}$ to collect and manage study data, and SAS 9.4 (SAS Institute) for analyses.

\section{Patient and public involvement}

Families of pediatric patients were involved at all stages of the research process, including designing the study, developing the family safety reporting method, refining data forms, co-producing the intervention, interpreting findings, and writing the manuscript to disseminate the intervention and findings. To facilitate family member involvement, we formed a 15 member Family Advisory Council that was chaired by leading national patient safety advocates (HH, DAM) and included parents from all participating study sites. Family members also actively participated in all subcommittees of the study, including the study's coordinating council (the study leadership group), scientific oversight committee, and the various subcommittees responsible for developing each element of the intervention (eg, written communication tool, campaign, and rounds subcommittees). At some sites, families also participated in physician trainings about the 
intervention and in rounds observations to provide feedback to the team about their communication on bedside rounds. We identified family members through their participation as advisors in our previous research, through facilitated introductions by site investigators (typically through family advisory councils at participating sites), and through national patient advocacy organizations.

\section{Results}

\section{Sample characteristics}

We reviewed 3106 patient admissions (1574 preintervention, 1532 post-intervention) for medical errors and adverse events, or a total of 13171 patient days (6326 pre-intervention, 6845 post-intervention). This represented all patients admitted on the study units during the study period. Patient characteristics were similar in pre-intervention and post-intervention periods, including age, race, insurance, number of complex chronic conditions, and length of stay (table 1).

Overall, 2148 parents ( $83.6 \%$ of those approached), 435 nurses (97.3\%), 586 residents (95.6\%), and 203 medical students $(99.5 \%)$ consented to participate in the study. We collected data from 2034 family safety interviews (95.9\% response rate) and 1224 family experience surveys (97.8\% response rate) and conducted 654 rounds observations.

\section{Medical errors and adverse events}

After implementation of the intervention, the overall medical error rate (the sum of harmful and nonharmful errors) did not significantly change (41.2 per 1000 patient days, 95\% confidence interval 31.2 to 54.5 pre-intervention $v 35.8,26.9$ to 47.7 postintervention, $\mathrm{P}=0.21$ ) (table 2). However, harmful errors (ie, preventable adverse events) decreased (20.7 (15.3 to 28.1) v 12.9 (8.9 to 18.6 ), $\mathrm{P}=0.01)$. Nonharmful errors were unchanged (20.0 (13.2 to 30.2) $v$ 22.0 (15.1 to 32.1), $\mathrm{P}=0.50)$. Non-preventable adverse events also decreased (12.6 (8.9 to 17.9) $\vee 5.2$ (3.1 to 8.8$), \mathrm{P}=0.003)$. Box 3 provides examples of nonharmful errors, harmful errors, and non-preventable adverse events.

\section{Sensitivity analysis}

Excluding incidents detected solely through family safety interviews had no substantive effect on our main findings. Using this metric, overall rates of medical errors remained unchanged pre-intervention versus post-intervention (36.4 (26.9 to 49.1) pre-intervention $v 31.4$ (23.1 to 42.8) post-intervention, $\mathrm{P}=0.22$ ). Harmful errors (ie, preventable adverse events) decreased significantly (18.3 (13.3 to 25.3) v 10.7 (7.2 to 16.1 ), $\mathrm{P}=0.01$ ) (see supplementary table 1 ).

\section{Family experience}

Top box ratings for six of 25 items of family experience improved, including family assessment of understanding on rounds $53.9 \%$ (95\% confidence interval $44.6 \%$ to $63.0 \%$ ) pre-intervention $v 62.8 \%$ (53.7\% to $71.1 \%$ ) post-intervention, $\mathrm{P}=0.03$ ), receipt of written updates (15.6\% (8.9\% to $25.9 \%) \vee 33.7 \%$ (23.9\% to $45.2 \%), \mathrm{P}<0.001)$, and understanding of written updates $(46.5 \%$ (34.2\% to $59.3 \%) \vee 57.9 \%$ (46.4\% to $68.6 \%$ ), $\mathrm{P}=0.04$ ) (fig 1). Several items pertaining to family experience with nurses also significantly improved post-intervention, including shared understanding with nurses $(55.3 \%$ (48.0\% to $62.4 \%) \vee 65.4 \%(58.4 \%$ to $71.8 \%), \quad \mathrm{P}=0.02)$, whether nurses addressed concerns (61.2\% (53.4\% to $68.5 \%) \vee 70.2 \%(62.9 \%$ to $76.6 \%), \mathrm{P}=0.02)$, and whether nurses made family members feel a part of the healthcare team $(63.2 \%$ (53.5 to 71.9$)$ v $70.7 \%$ (61.4\% to $78.6 \%), \mathrm{P}=0.04)$.

No significant improvements in family experience occurred specifically with physicians postintervention, including shared understanding with physicians (54.0\% (44.6\% to 63.1\%) v 59.2\% (49.9\% to $67.8 \%), \mathrm{P}=0.14)$, whether physicians addressed concerns $(61.8 \%$ (52.5\% to $70.3 \%) \vee 65.9 \%$ (56.8\% to $73.8 \%), P=0.22$ ), and whether physicians made family members feel a part of the healthcare team (57.7\% (45.9 to 68.7$) \vee 60.9 \%$ (49.2\% to $71.4 \%)$ $\mathrm{P}=0.34)$. However, family understanding on rounds and receipt and understanding of written updates, reflected communications between physicians, nurses, and families.

No components of family experience worsened significantly. Overall experience with hospital stay was unchanged.

\section{Communication processes}

Family centered rounds occurred more frequently post-intervention $\quad(72.2 \% \quad(53.5 \%$ to $85.4 \%) \quad v$ $82.8 \%$ (64.9\% to $92.6 \%), \mathrm{P}=0.02)$. Top box family engagement on rounds improved significantly $(55.6 \%$ (32.9\% to $76.2 \%$ ) v $66.7 \%$ ( $43.0 \%$ to $84.1 \%$ ), $\mathrm{P}=0.04$ ), as did nurse engagement (20.4\% (7.0\% to $46.6 \%) v$ $35.5 \%$ (17.0\% to 59.6\%), P=0.03) (fig 2). Frequency of teaching on rounds was unchanged $(73.4 \%$ (46.0\% to $90.0 \%) \vee 72.4 \%$ (45.3\% to $89.3 \%), \mathrm{P}=0.78)$.

\begin{tabular}{|c|c|c|c|c|c|}
\hline \multirow[b]{2}{*}{ Incident type } & \multicolumn{2}{|c|}{ Pre-intervention $(n=1574)$} & \multicolumn{2}{|c|}{ Post-intervention $(n=1532)$} & \multirow[b]{2}{*}{$P$ value } \\
\hline & No of incidents & $\begin{array}{l}\text { Rate } / 1000 \text { patient } \\
\text { days }(95 \% \mathrm{Cl})\end{array}$ & No of incidents & $\begin{array}{l}\text { Rate } / 1000 \text { patient } \\
\text { days }(95 \% \mathrm{Cl})\end{array}$ & \\
\hline Overall medical errors & 259 & $41.2(31.2$ to 54.5$)$ & 245 & $35.8(26.9$ to 47.7$)$ & 0.21 \\
\hline Non-harmful errors & 139 & $20.0(13.2$ to 30.2$)$ & 164 & $22.0(15.1$ to 32.1$)$ & 0.50 \\
\hline Harmful errors* & 120 & 20.7 (15.3 to 28.1$)$ & 81 & $12.9(8.9$ to 18.6$)$ & 0.01 \\
\hline Non-preventable adverse events & 72 & 12.6 (8.9 to 17.9$)$ & 31 & $5.2(3.1$ to 8.8$)$ & 0.003 \\
\hline
\end{tabular}


Box 3: Examples of medical errors and adverse events

\section{Non-harmful errors}

- 9 year old admitted for leg pain-historical information in care plan inaccurately listed patient as having sickle cell anemia

- 14 year old with severe cerebral palsy-blood cultures not obtained as directed when patient spiked a fever

- 11 year old with exacerbation of cystic fibrosis-dose of antibiotics missed (eight hour delay)

- 1 week old infant with jaundice-unintentionally received an extra dose of vitamin D after miscommunication on transfer between two units

- 3 year old with neurological abnormalities and gastrostomy dependence-flow sheet had been set for incorrect age (5-12 year) causing risk for improper documentation

- 2 month old with congenital heart disease-contrary to care plan, was given a $50 \mathrm{~mL}$ bolus feed instead of planned very gradual $5 \mathrm{~mL} / \mathrm{h}$ advance

- 6 year old with metabolic disorder on a special metabolic formula diet- received six bottles of incorrect metabolic formula (missing a key ingredient) before the error was recognized

- 9 year old with lymphadenitis-delay in vancomycin being administered due to pump failure

Harmful errors (ie, preventable adverse events)

- 4 month old with suspected mitochondrial disorder-delay in treatment to address vomiting, low albumin, and increased partial thromboplastin time due to lost blood samples

- 3 month old with congenital heart disease-nasopharyngeal airway inadvertently inserted into esophagus and desaturations experienced

- 4 year old admitted with history of drop attacks and seizures (also with history of vertigo consistently before events)-fell and hit head after a seizure while being transferred from wheelchair to chair

- 17 year old with inflammatory bowel disease flare-two day delay in consultation with pain treatment service; patient ultimately required a narcotic drip for pain control

- 3 month old receiving parenteral nutrition for failure to thrive-experienced hypoglycemia requiring glucose injection due to delayed recognition of malfunctioning total parenteral nutrition pump

- 2 month old admitted for fever and upper respiratory tract symptoms-became infected with norovirus while in hospital

- 2 month old with feeding intolerance and failure to thrive on nasogastric feeds-failed to gain weight due to incorrect volume of feeds being given

- 16 year old with chromosomal abnormality, seizure disorder-developed skin breakdown from oxygen tubing

Non-preventable adverse events

- 10 month old with urosepsis-delay in drawing follow-up laboratory tests and correcting electrolyte disturbances due to difficulty in taking blood samples

- 12 year old receiving chemotherapy who developed hyperglycemia from steroids

- 16 year old with anal abscess and immunodeficiency-developed anaphylaxis while receiving immunotherapy (no history of previous reaction)

- 8 year old with Chiari malformation-developed Clostridium difficile colitis after surgical procedure

- 6 year old with bone marrow disorder-had intravenous infiltrate while out on pass with family

- 3 year old with complicated pneumonia requiring chest tubes-chest tube developed a clog with leak

- 13 year old who underwent endoscopic sinus surgery-developed postoperative emesis with narcotics for which ondansetron was required

- 12 year old with pneumonia-developed respiratory depression and over-sedation from narcotic treatment, requiring narcan

The average duration of rounds per patient did not significantly change post-intervention (8.5 minutes (95\% confidence interval 6.8 to 10.2 ) $v 10.2$ minutes ( 7.8 to 12.6$), P=0.13$ ). Frequency of adherence to key communication behaviors significantly improved, including families expressing concerns at the start of rounds $(18.2 \%$ (5.6\% to $45.3 \%) \vee 37.7 \%(17.6 \%$ to $63.3 \%), \mathrm{P}=0.03)$ and synthesis being completed on rounds $(4.7 \%(0.7 \%$ to $25.2 \%) \vee 26.5 \%(12.7 \%$ to $47.3 \%$ ), $\mathrm{P}=0.02$ ) (fig 2). Parent reporting of child's illness severity (eg, better or worse) on rounds increased (28.8\% (13.0\% to 52.0\%) v 43.5\% (23.8\% to $65.4 \%), \mathrm{P}=0.08)$. Effective use of plain language on rounds remained unchanged $(28.8 \%$ (9.2\% to $62.5 \%)$ v $34.7 \%(12.6 \%$ to $66.3 \%), \mathrm{P}=0.36)$.

\section{Discussion}

In this seven center study, we found that although overall medical errors were unchanged, harmful medical errors decreased by $38 \%$ after implementation of a structured verbal and written communication intervention for rounds that emphasized health literacy, family engagement, and bidirectional communication. The improvements in harmful errors occurred without a statistically significant increase in duration of rounds or decrease in the amount of teaching on rounds. Additionally, our intervention was associated with improvements in key communication behaviors, family and nurse engagement on rounds, and several measures of family experience. Our findings suggest that implementing a standardized, structured programme to improve communication with patients, families, and the interprofessional team on rounds could improve patient safety and other outcomes. Our findings also provide an evidence base that supports calls by physician, ${ }^{27-29}$ nursing, ${ }^{30}$ and family $^{31} 32$ advocacy organizations to improve the family centeredness of care.

\section{Strengths and limitations of this study}

A major strength of our research was the method we used to systematically measure patient safety events across multiple hospitals. ${ }^{19} 33$ To our knowledge, the relation between healthcare provider-family communication and patient safety has not been systematically measured in a multicenter study in the inpatient setting. Other studies exploring 


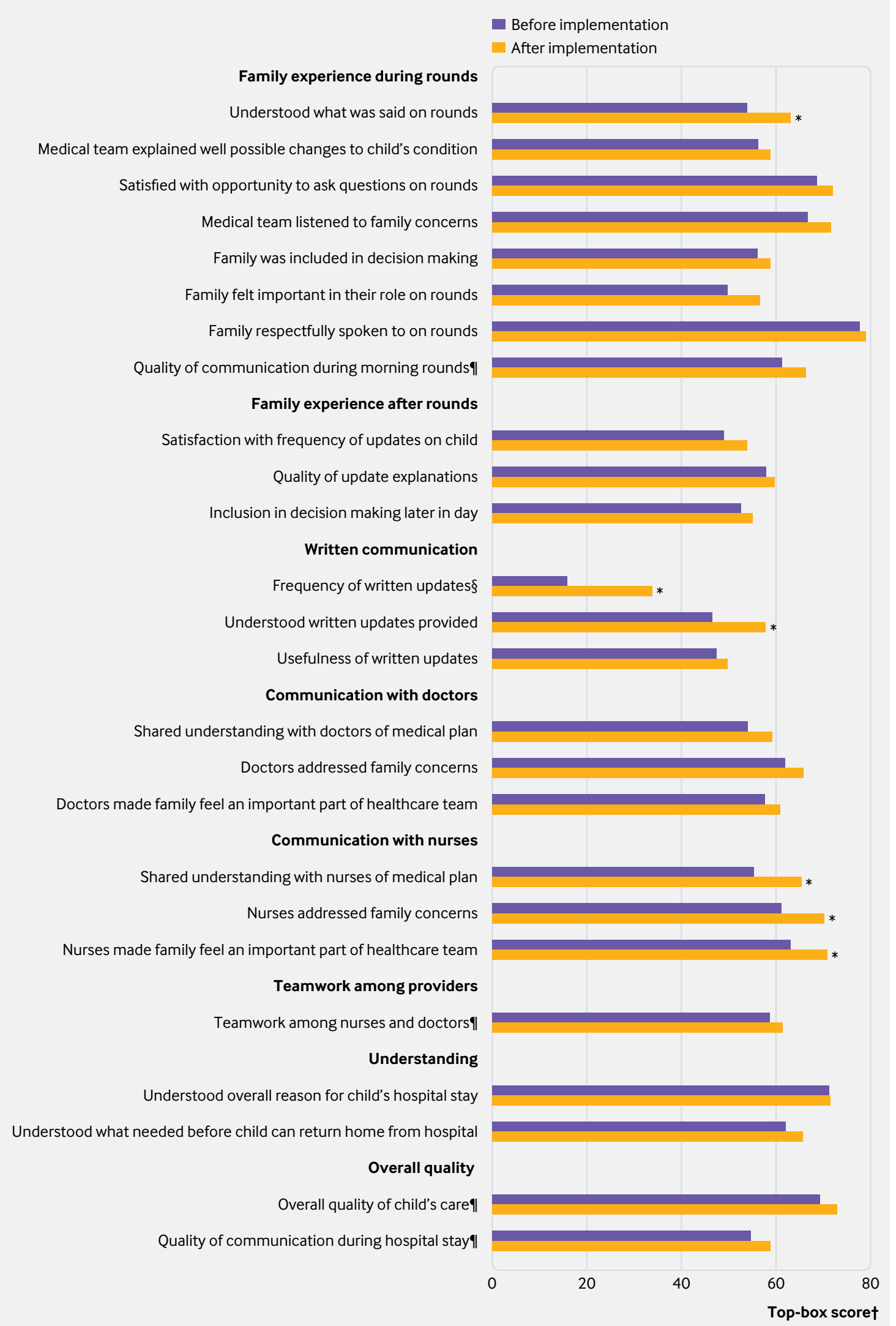

Fig 1 | Family experience before and after implementation of Patient and Family Centered I-PASS. Measured through surveys administered before discharge, six of 25 elements of family experience improved significantly after implementation of the intervention. *P<0.05. †Top box=top most response on a scale (eg, "excellent"). Response options for scale="Not at all”, "Slightly", "Somewhat”, "Very”, "Extremely", except when marked by § ("Never”, "Rarely”, “Sometimes”, “Usually”, “Always”) or १ (“Poor”, “Fair”, “Good”, “Very good”, “Excellent”) 

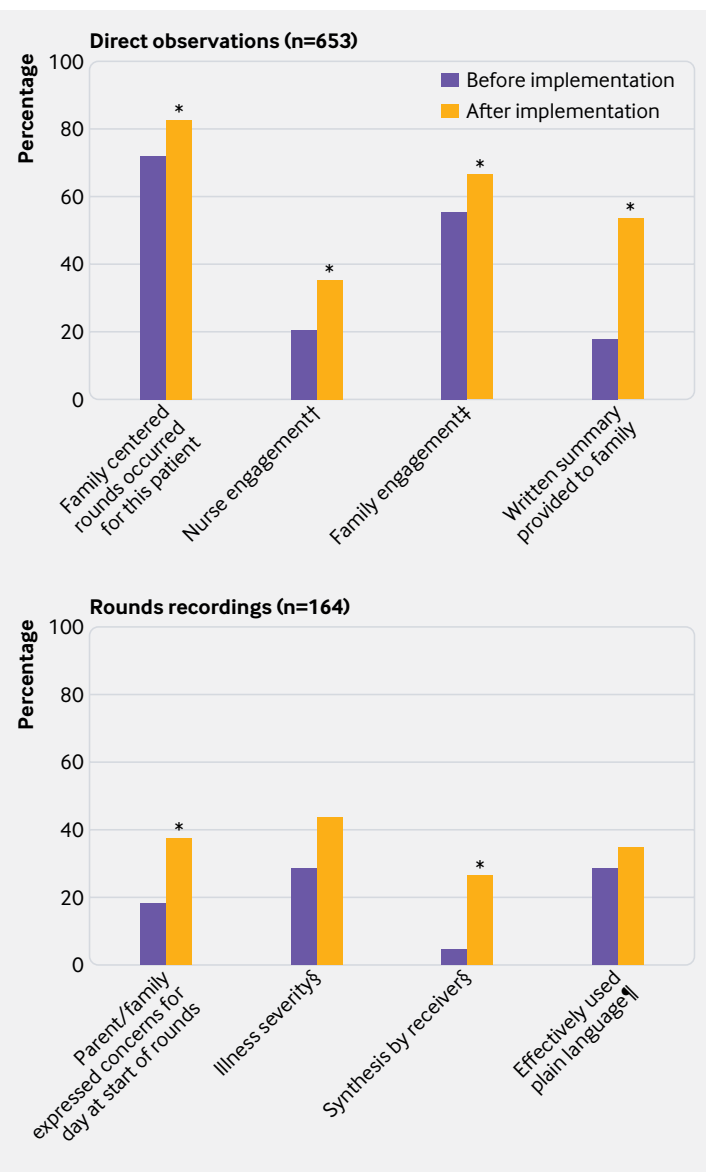

Fig 2 | Changes in rounds process data before and after implementation of Patient and Family Centered I-PASS based on: (top) real time structured direct observations of rounds and (bottom) post hoc analyses of audio recordings of a subset of rounds observations. After implementation of the intervention, frequency of family centered rounds, nurse and family engagement on rounds, and provision of written summaries to families significantly increased, as did families expressing concerns at the start of rounds and synthesizing (ie, reading back) key action items and contingency plans. Families reporting illness severity improved but not significantly. Effective use of plain language by providers on rounds was unchanged. †Top-box $=5$, "Nurse present and paying attention to rounds. Answers questions, asks questions, and speaks up to fill in missing details and correct misinformation without prompting". ¥Top box $=5$, "Family completely engaged in rounds. Answered questions, asked questions, and spoke up to fill in missing details and correct misinformation without prompting”. §Top-box=3, "Yes, completely". ๆTopbox=4, "To a great extent"

healthcare provider-patient or healthcare providerfamily communication were single center, ${ }^{34}$ did not systematically measure safety outcomes, ${ }^{35}{ }^{36}$ or occurred in the setting of outpatient family medicine. ${ }^{37}$ Our multicenter design allowed us to sample a large number of patients $(>3000)$ from diverse backgrounds (22\% Latino, 15\% black/African-American, $10 \%$ limited English proficiency). The size and scope of our study makes it one of the largest studies of healthcare provider-family communication performed to date.
Another strength of our study is that we integrated family safety reporting into our two step surveillance method. Unlike other studies using systematically measured patient safety outcomes, we actively solicited family safety reports and handled data collected from family reports of medical errors and adverse events the same as data collected from any other source (eg, provider reports, hospital incident reports) by having these reports systematically investigated and rated by our team of nurse and physician reviewers. The decision to include these data was predicated on previous research we conducted that validated the use of families as a source of patient safety data. ${ }^{1933}$

A third strength of our study, as well as our intervention, is that co-production with families informed all aspects of the project, which we believe greatly improved the quality of data we collected, and the potency of the intervention. We sought to prioritize family involvement as a key component of a multidisciplinary collaboration that involved nurses, physicians, researchers, medical educators, communication experts, and health literacy experts in all aspects of study design, implementation, data collection and analysis, and interpretation and dissemination of findings.

Our study has several limitations. First, our study design precludes establishing causality between the intervention and error rates or other outcomes. Studies of quality and safety improvement interventions are often not amenable to classic randomized trial designs. ${ }^{838}$ Because we believed that our intervention was highly unlikely to harm patients, our lack of equipoise precluded patient level randomization or a crossover design. We opted against a step-wedge design for pragmatic reasons, including the logistical difficulty of randomizing the timing of introducing a complex intervention involving physicians, nurses, and families, and ensuring that no simultaneous cointerventions were occurring that might confound results. Because our before and after intervention design is at risk of confounding due to secular trends, we cannot be certain that it was our intervention that caused the improvements in patient safety that we observed. However, previous research ${ }^{39-41}$ suggests that a change in harmful errors of the magnitude we observed is unlikely to have occurred from secular trends alone, especially over such a short period. Additionally, given that we observed concurrent improvements in rounds communication processes, family experience, and patient safety outcomes as hypothesized, and because findings were generated from data gathered across seven sites (limiting the possibility that changes were due to unmeasured site specific confounders), we believe that the changes observed were related to the intervention.

Another limitation is that medical error and adverse event classification is a complex and imperfect process that could lead to misclassification. ${ }^{6}{ }^{8}$ The reliability of our ratings was similar to or better than previous studies, however, and we reconciled all discordant classifications. ${ }^{68}$ Moreover, because final error and 
adverse event classifications were made only after post-intervention data collection was complete and performed by secondary reviewers blinded to preintervention and post-intervention status, it is unlikely that reviewer bias could explain the significant differences in preventable adverse event and total adverse event rates observed.

Thirdly, although rates of limited English proficiency $^{42}$ and lower education levels ${ }^{43}$ in our study population were fairly representative of the overall US population, most parents in our sample reported speaking and reading English well and had attended some college. It is possible that patient engagement and other results might differ in populations with more limited health literacy. To minimize this concern, our intervention included health literacy training and reinforced the use of health literacy principles in daily communications to deal with the needs of families with lower levels of education or health literacy.

Finally, adherence to some aspects of the designed intervention varied, including the extent of nurse engagement, use of plain language, and frequency of synthesis of plans by family members on rounds. Improvements were modest for some process measures and outcomes. Despite imperfect adherence, we found improvements in safety and quality outcomes postimplementation, suggesting that further refining the intervention, improving its implementation, and focusing on culture change might lead to greater improvements in patient safety. As iterative changes are made, future research should continue to measure the effectiveness and sustainability of the intervention, particularly as the current project gathered data for a relatively short period post-intervention.

Although improvement in rates of harmful errors occurred despite limited adherence to some processes and only modest improvements in secondary outcomes and process measures (eg, family experience, nurse/ family engagement on rounds), this pattern is typical of what we and others have observed when introducing a "bundle" of complementary safety improvements. For example, one study found major improvements in surgical mortality after implementation of a landmark surgical checklist, despite only 57\% adherence with all six safety process indicators tracked post-intervention. ${ }^{38}$ Likewise, despite marked improvements in safety, adherence to key processes was less than $50 \%$ in the previous I-PASS Resident Handoff Study. ${ }^{8}$ The concept of an "accident chain" (where multiple process vulnerabilities and failures in sum, rather than one sole cause, lead to an accident) could explain this. ${ }^{44} 45$ An improved decision or work process at any of these points can potentially interrupt the chain and avert the accident; consequently, even a modest process improvement at one step, coupled with complementary modest process improvements at other steps in the process, can yield major benefits. Patient safety bundles act to influence decisions and processes at multiple steps in the accident chain. Our intervention might have similarly served to improve safety.

\section{Comparisons to other research}

As evidence has accumulated that efforts to decrease miscommunications between healthcare providers are associated with improvements in patient safety, relatively little research has tackled whether efforts to mitigate other types of communication failures, including healthcare providers' miscommunications with patients and families, might be associated with patient safety benefits. ${ }^{34} 46$ Some evidence suggests that improved teamwork might be associated with improved patient outcomes, ${ }^{4748}$ but empirical evidence about the relation between patient/family centered care and patient safety is limited. ${ }^{34} 46$ A recent single center study in adults in intensive care units showed that a multifaceted intervention emphasizing patient and care giver engagement and communication was associated with reductions in preventable adverse events and improvements in patient and care giver experience. ${ }^{34}$ Our multicenter study extends this work by demonstrating application beyond a single intensive care unit setting and suggests the ability to generalize a family centered communication programme across multiple centers. Our study also included a novel approach to family safety reporting.

Our current study also addresses several limitations of a previous single center study conducted by our group, in which we found that implementing a family centered, interprofessional night time communication intervention bundle was associated with improved parent and provider experience and shared understanding. ${ }^{13}$ We greatly refined the intervention to better integrate it into provider workflow and more effectively engage families and nurses in all study aspects. Importantly, we also directly measured safety outcomes using an expanded active surveillance methodology that included family safety reporting. ${ }^{33}$

\section{Meaning, implications, and future research}

Our finding that harmful errors decreased after our intervention was consistent with our study's central hypothesis. It could be that improving family communication decreases harmful medical errors because families serve as an extra safeguard in care (eg, vigilant partners who can detect hazardous circumstances and errors early in their evolution) before errors lead to harm.

The fact that rates of overall medical errors did not change significantly in our study was unexpected, and seems to have been secondary to a lack of change in non-harmful errors, suggesting that our intervention might have differentially affected harmful and nonharmful errors. Further research is needed to further explore the causal links between our intervention and harmful and non-harmful errors. Robust experimental or quasi-experimental study designs with control groups could help shed further light on this issue.

The marked reduction in adverse events determined to be non-preventable was unexpected. We trained raters to classify adverse events as non-preventable if evidence was not found to establish that an adverse event was caused by an error. While our adjudication 
method is well established and performed reliably in this study, it might be overly restrictive at times and could underestimate the number of adverse events that are preventable. Additionally, the understanding of adverse event preventability has evolved over time in patient safety. For example, hospital acquired central line infections were once generally considered nonpreventable because there is typically no observable break in sterile technique or other observable error that results in infection. We now know, however, that interventions can prevent nearly $80 \%$ of central line infections, and thus these types of infections are generally considered preventable. ${ }^{49} 50$ In a similar way, it is possible that improved communication and engagement with patients and families might prevent or preclude the opportunity for some adverse events to occur through mechanisms that are not immediately apparent. Additional research is required to further explore this possibility.

The improvement in families' reported experience with nurses but not physicians was also of interest. These results might reflect the fact that nurses typically spend more time at the bedside than physicians; thus improvements in overall team communication may be more readily reflected in nursing metrics. Alternatively, nurses might have experienced a greater relative change in their roles and involvement in rounds, thus leading to larger improvements in ratings of their communications with families. Despite the observed improvement in nurse engagement on rounds, the changes were modest, indicating that there remains room for greater engagement. Nevertheless, our findings were consistent with what we found in our pilot study in that family reports of experience with nurses improved after implementation of a family centered interprofessional night time communication intervention. ${ }^{13}$ Taken together, these findings suggest that small improvements in nursing engagement might lead to larger overall improvements in patient experience. The effect on family experience of improving nursing engagement on rounds and nursephysician communication warrants further study.

Also worthy of further study is whether our intervention could be adapted for use in adult patient populations. We posit that with modifications of the intervention, our intervention could be applied to diverse settings and patient populations beyond pediatrics, including adult medicine, intensive care, geriatric medicine, long term care and rehabilitation, and oncology. Our intervention also occurred in academic centers and further study is warranted to examine its effectiveness in non-academic centers.

We found that while changing routine hospital work processes and culture to effectively incorporate patients' and families' voices required a substantial investment of time and effort, doing so has the potential to yield important improvements in harmful errors and experience of care. Further refinements of our intervention are ongoing, which may facilitate making these changes in a manner that could lead to greater improvements with decreased effort and cost.

\section{Conclusion}

An intervention to improve healthcare provider-family communication was associated with a reduction in harmful medical errors, reductions in adverse events, improvements in family experience, and improvements in communication processes, although overall errors did not change. These improvements, studied in multiple hospitals, occurred without a major increase in duration of rounds or reduction in teaching. Further research is required to test the sustainability and feasibility of our intervention, as well as its generalizability across diverse health systems, specialties, populations, settings, and hospital types. However, our intervention, with its focus on structured communication, health literacy, family engagement, and bidirectional communication, is likely to be applicable, with adaptation, to a broad range of settings. Our study highlights the value of coproducing interventions and research with families and interprofessional stakeholders in a manner that truly incorporates their input at all stages. Structuring communication between healthcare providers and patients and families to better meets the needs of both could be an important, as yet underappreciated, means to improve the safety of patient care.

\section{AUTHOR AFFILIATIONS}

${ }^{1}$ Harvard Medical School, Boston, MA, USA

'Department of Medicine and Division of General Pediatrics, Boston Children's Hospital, Boston, MA, USA

${ }^{3}$ Drexel University College of Medicine, Philadelphia, PA, USA

${ }^{4}$ Department of Pediatrics, St Christopher's Hospital for Children, Philadelphia, PA, USA

Institute for Nursing and Interprofessional Research, Children's Hospital Los Angeles, Los Angeles, CA, USA

${ }^{6}$ Family-Centered Care Department, Lucile Packard Children's Hospital Stanford, Palo Alto, CA, USA

${ }^{7}$ University of California San Francisco School of Medicine, San Francisco, CA, USA

${ }^{8}$ Department of Pediatrics, Benioff Children's Hospital, San Francisco, CA, USA

${ }^{9}$ Department of Medicine and Division of General Pediatrics, Boston Children's Hospital, Boston, MA, USA

${ }^{10}$ Office of Experience, Boston Children's Hospital, Boston, MA, USA ${ }^{11}$ Inpatient Medicine, Boston Children's Hospital, Boston, MA, USA

${ }^{12}$ Center for Patient Safety Research, Division of General Medicine, Department of Medicine at Brigham and Women's Hospital, Boston, MA, USA

${ }^{13}$ University of Cincinnati College of Medicine, Cincinnati, OH, USA ${ }^{14}$ Department of Pediatrics, Cincinnati Children's Hospital Medical Center, Cincinnati, OH, USA

${ }^{15}$ University of California San Diego School of Medicine, San Diego, CA, USA

${ }^{16}$ Division of Pediatric Hospital Medicine, Rady Children's Hospital San Diego, San Diego, CA, USA

${ }^{17}$ Pediatrics, University of Toronto, Toronto, ON, Canada

${ }^{18}$ Department of Pediatrics, Hospital for Sick Children, Toronto, ON, Canada

${ }^{19}$ Faculty of Nursing, University of Toronto, Toronto, ON, Canada ${ }^{20}$ Division of Pediatric Hospital Medicine, Hospital for Sick Children, Toronto, ON, Canada

${ }^{21}$ Stanford School of Medicine, Palo Alto, CA, USA

${ }^{22}$ Lucile Packard Children's Hospital Stanford, Palo Alto, CA, USA

${ }^{23}$ University of Utah School of Medicine, Salt Lake City, UT, USA

${ }^{24}$ Department of Pediatrics, Primary Children's Hospital, Salt Lake City, UT, USA

${ }^{25}$ Family Advisory Council, St Christopher's Hospital for Children, Philadelphia, PA, USA

${ }^{26}$ Uniformed Services University of the Health Sciences, Walter Reed National Military Medical Center, Bethesda, MD, USA

${ }^{27}$ Walter Reed National Military Medical Center, Bethesda, MD, USA

${ }^{28}$ Mothers Against Medical Error, Columbia, SC, USA 
${ }^{29}$ Family Partner Program, St Louis Children's Hospital, St Louis, MO, USA

${ }^{30}$ St Louis Children's Hospital, St Louis, MO, USA

${ }^{31}$ The Justin's HOPE Project, Task Force for Global Health, Decatur, GA, USA

${ }^{32}$ New York State Department of Health, New York, NY, USA

${ }^{33}$ Office of Minority Health \& Health Disparities Prevention, Corning

Tower, Empire State Plaza, Albany, NY, USA

${ }^{34} \mathrm{New}$ York University School of Medicine, New York, NY, USA

${ }^{35}$ Division of Developmental-Behavioral Pediatrics, New York University Langone Medical Center, New York, NY, USA

${ }^{36}$ Departments of Pediatrics and Population Health at New York University Langone Medical Center, New York, NY, USA

${ }^{37}$ Cohen Children's Medical Center, New York, NY, USA

${ }^{38}$ Hofstra Northwell School of Medicine, Queens, NY, USA

${ }^{39}$ University of Hawaii John A Burns School of Medicine, Honolulu, HI, USA

${ }^{40}$ Hawai'i Pacific Health, Honolulu, HI, USA

${ }^{41}$ Brigham and Women's Hospital, Boston, MA, USA

\section{Group authorship}

The Patient and Family Centered I-PASS Study Group includes all authors listed in the byline, as well as the following: Brenda $\mathrm{K}$ Allair, Claire Alminde, Marisa Atsatt, Megan E Aylor, James F Bale, Jr, Dorene Balmer, Kevin Barton, Carolyn E Beck, Debra Chandler, Amanda Choudhary, Eileen Christensen, Sally Coghlan-McDonald, F Sessions Cole, Sarah Collins, Elizabeth Corless, Roxi Da Silva, Amanda S Growdon, LeAnn Gubler, Roben Harris, Michele Lane, Christy JW Ledford, Christopher G Maloney, Peggy Markle, Fernando Mendoza, Alexandra N Mercer, Katherine A O'Donnell, Mary Ottolini, Rita Pickler Matthew W Ramotar, Lee M Sanders, Kimberly Sauder, Samir S Shah, Meesha Sharma, Arabella Simpkin, Laura Trueman, Tanner Trujillo, Cindy Warnick, Chelsea Welch, Andrew J White, Matthew F Wien, Ariel S Winn, and Stephanie Wintch.

Affiliations of Patient and Family Centered I-PASS Study Group: Benioff Children's Hospital, San Francisco, CA, USA (CoghlanMcDonald); Boston Children's Hospital, Boston, MA, USA (Allair, Mercer, Ramotar, Sharma); Boston Children's Hospital/Harvard Medical School, Boston, MA, USA (Growdon, O'Donnell, Winn); Brigham and Women's Hospital, Boston, MA, USA (Wien); Children's Hospital of Philadelphia/Perelman School of Medicine at the University of Pennsylvania, Philadelphia, PA, USA (Balmer); Children's National Health System/George Washington University School of Medilcine and Health Sciences, Washington, DC, USA (Ottolini); Cincinnati Children's Hospital Medical Center, Cincinnati, OH, USA (Chandler, Trueman); Cincinnati Children's Hospital Medical Center/ University of Cincinnati College of Medicine, Cincinnati, OH, USA (Shah); Columbia University, New York, NY, USA (Collins); Doernbecher Children's Hospital/Oregon Health and Science University, Portland, OR, USA (Aylor); Hospital for Sick Children/University of Toronto, Toronto, ON, Canada (Beck); Lucile Packard Children's Hospital Stanford, Palo Alto, CA, USA (Atsatt, Wintch); Lucile Packard Children's Hospital Stanford/Stanford School of Medicine, Stanford, CA, USA (Mendoza, Sanders); Massachusetts General Hospital/Harvard Medical School, Cambridge, MA, USA (Simpkin); Ohio State University College of Nursing, Colombus, OH, USA (Pickler); Primary Children's Hospital, Salt Lake City, UT, USA (Choudhary, Christensen, Corless, Gubler, Trujillo, Warnick, Welch); Primary Children's Hospital/University of Utah School of Medicine, Salt Lake City, UT, USA (Bale, Maloney); St Christopher's Hospital for Children, Philadelphia, PA, USA (Alminde); St Louis Children's Hospital, St Louis, MO, USA (Harris, Lane, Sauder); St Louis Children's Hospital/Washington University School of Medicine in St Louis, St Louis, MO, USA (Barton, Cole, White); Uniformed Services University of the Health Sciences, Bethesda, MD, USA (Ledford); and Walter Reed National Military Medical Center, Bethesda, MD, USA (DaSilva, Markle).

We thank the members of the I-PASS Study Group, patients, families, residents, nurses, and medical students who participated in the study; faculty members and nurses who participated on family centered rounds; the following people who played key contributory roles: Tanya Agnihotri (Hospital for Sick Children, Toronto, ON); Sahar Ameri (University of Utah School of Medicine, Salt Lake City, UT); Khushali Amin (St Christopher's Hospital for Children, Philadelphia, PA); Cindy Brach (Agency for Healthcare Research and Quality, Rockville, MD); Vincent Chiang (Boston Children's Hospital/Harvard Medical School, Boston, MA); Juanita Dudley (Cincinnati Children's Hospital Medical Center, Cincinnati, $\mathrm{OH}$ ); Jonathan Finkelstein (Boston Children's Hospital/Harvard Medical School); Jacquelin Foss (University of Utah School of Medicine, Salt Lake City, UT); Caitlin Gallagher-Lacey (University of Utah School of Medicine, Salt Lake
City, UT); Janet Gehring (Walter Reed National Military Medical Center, Bethesda, MD); Brian Gin (Benioff Children's Hospital/University of California San Francisco School of Medicine, San Francisco, CA); Molly Gove (St Christopher's Hospital for Children, Philadelphia, PA); Alicia Harnett (Stanford School of Medicine, Palo Alto, CA); Joseph A Jabour (Cincinnati Children's Hospital Medical Center, Cincinnati, $\mathrm{OH}$ ); Mia Johnson (Walter Reed National Military Medical Center, Bethesda, MD); Logan Maag (Cincinnati Children's Hospital Medical Center, Cincinnati, $\mathrm{OH}$ ); Rolando Merino (Walter Reed National Military Medical Center, Bethesda, MD); Vineeta Mittal (University of Texas South-western Medical Center, Dallas, TX); Bhanu Muniyappa (University of Utah School of Medicine, Salt Lake City, UT); Iris Paredes (Lucile Packard Children's Hospital, Palo Alto, CA); Christina Pinard (Walter Reed National Military Medical Center, Bethesda, MD); Janet Porterfield (Walter Reed National Military Medical Center, Bethesda, MD); Michelle Rait (Benioff Children's Hospital, San Francisco, CA); Caitlin Rower (University of Utah School of Medicine, Salt Lake City, UT); Mark Schuster (Kaiser Permanente School of Medicine, Pasadena, CA); Kelly Short (St Christopher's Hospital for Children, Philadelphia, PA); Ben Shoults (Boston Children's Hospital/Harvard College, Boston, MA); Helen Simonowitz (St Christopher's Hospital for Children, Philadelphia, PA); Sherry Stein (Hospital for Sick Children, Toronto, ON); Kimberly Stowers (University of Utah School of Medicine, Salt Lake City, UT); Nadia Tavernese (Hospital for Sick Children, Toronto, $\mathrm{ON}$ ); and Brooke Wiedinmyer (Benioff Children's Hospital, San Francisco, CA).

Contributors: All authors conceived and designed the study; contributed to the acquisition, analysis, or interpretation of data; content; and critically revised the report and agreed to submit the report for publication. CPL supervised the study. AK and CPL obtained funding and drafted the initial manuscript. BMG provided administrative support. SL and CSY had full access to the data and take responsibility for the integrity of the data and the accuracy of the statistical analysis. AK is responsible for the overall content as guarantor and accepts full responsibility for the work and conduct of the study. The corresponding author attests that all listed authors meet authorship criteria and that no others meeting the criteria have been omitted.

Funding: This project was supported by grant CDR-1306-03556 from the Patient-Centered Outcomes Research Institute (principal investigator: (PL). AK was supported by grant K12HS022986 from the Agency for Healthcare Research and Quality (principal investigator: Jonathan Finkelstein; Boston Children's Hospital, Boston, MA). JDB was supported by grant 5T32HS00063-21 from the Agency for Healthcare Research and Quality (principal investigator: Jonathan Finkelstein). The funders had no role in the design of the study; in the collection, analysis, or interpretation of data; in the writing of the report; or in the decision to submit the article for publication. Researchers were independent from funders and all authors had full access to the data and can take responsibility for the integrity of the data and the accuracy of the data analysis.

Competing interests: All authors have completed the ICMJE uniform disclosure form at www.icmje.org/coi disclosure.pdf and declare no associations with commercial entities that provided support for the work reported in the submitted manuscript. JFB, AKD, CPL, SJP, TCS, SSS, NDS, AIS, and DCW hold equity in the I-PASS Patient Safety Institute. RS works for Intermountain Healthcare, which holds equity in the I-PASS Patient Safety Institute. SC, JKO'T, and SJP hold stock options in the I-PASS Patient Safety Institute. SC, CPL, JKO'T, SJP, GR, TCS, NDS, AJS, and DCW have consulted with the I-PASS Patient Safety Institute. The I-PASS Patient Safety Institute is a company that seeks to train institutions in best handoff practices and aid in their implementation. The current study was designed before the I-PASS Patient Safety Institute was conceived of as an entity and the I-PASS Patient Safety Institute is not involved in bedside rounds or familycentered care and was in no way involved in this study. Moreover, to ensure objectivity, all data were sent directly from the sites to the statistical team at the Data Coordinating Center, who do not have any involvement with the I-PASS Patient Safety Institute. All analyses were conducted by this statistical team. TCS, NDS, AJS, and DCW have received monetary awards, honorariums, and travel reimbursement from multiple academic and professional organizations for teaching and consulting on physician performance and handoffs. CPL and RS are supported in part by the Children's Hospital Association for their work as executive council members of the Pediatric Research in Inpatient Settings (PRIS) network. RS has received monetary awards, honorariums, and travel reimbursement from multiple academic and professional organizations for talks about pediatric hospitalist research networks and quality of care. CPL has also served as a paid consultant to Virgin Pulse to help develop a Sleep and Health 
Program. In addition, CPL has received monetary awards, honoraria, and travel reimbursement from multiple academic and professional organizations for teaching and consulting on sleep deprivation, physician performance, handoffs, and safety, and has served as an expert witness in cases regarding patient safety and sleep deprivation. All other authors have no conflicts of interest to disclose at this time.

Ethical approval: This study was approved by Boston Children's Hospital (BCH) institutional review board (IRB-P00012045) and participating institutions' institutional review boards, either through individual site approval or reliance agreements with $\mathrm{BCH}$. Participants gave informed consent before taking part. We obtained waivers of consent to review patient charts.

Data sharing: Individual participant data collected during the trial, after deidentification, can be made available to interested parties who follow the process outlined in the supplementary data sharing plan. No other documents are available.

Transparency: The lead author (AK) affirms that this manuscript is an honest, accurate, and transparent account of the study being reported; that no important aspects of the study have been omitted; and that any discrepancies from the study as originally planned (and, if relevant, registered) have been explained.

This is an Open Access article distributed in accordance with the Creative Commons Attribution Non Commercial (CC BY-NC 4.0) license, which permits others to distribute, remix, adapt, build upon this work non-commercially, and license their derivative works on different terms, provided the original work is properly cited and the use is noncommercial. See: http://creativecommons.org/licenses/by-nc/4.0/.

1 Makary MA, Daniel M. Medical error-the third leading cause of death in the US. BMJ 2016;353:i2139. doi:10.1136/bmj.i2139

2 Institute of Medicine. To Err is Human: Building a Safer Health System. The National Academies Press, 2000.

3 World Health Organization Regional Office for Europe. Data and statistics. www.euro.who.int/en/health-topics/Health-systems/ patient-safety/data-and-statistics (accessed 24 Oct 2018).

4 World Health Organization Regional Office for Europe. A Brie Synopsis on Patient Safety. World Health Organization: Copenhagen, 2010. www.euro.who.int/en/health-topics/Health-systems/patientsafety/publications2/2010/a-brief-synopsis-on-patient-safety.

5 The Joint Commission. Sentinel event statistics released for 2014 Jt Comm Online 2015. www.jointcommission.org/assets/1/23/ jconline_April 29 15.pdf (accessed 24 Oct 2018).

6 Starmer AJ, Sectish TC, Simon DW, et al. Rates of medical errors and preventable adverse events among hospitalized children following implementation of a resident handoff bundle. IAMA 2013:310:2262-70. doi:10.1001/jama.2013.281961

7 Graham KL, Marcantonio ER, Huang GC, Yang J, Davis RB, Smith CC. Effect of a systems intervention on the quality and safety of patient handoffs in an internal medicine residency program. J Gen Intern Med 2013;28:986-93. doi:10.1007/s11606-013-2391-7

8 Starmer AJ, Spector ND, Srivastava R, et al, I-PASS Study Group. Changes in medical errors after implementation of a handoff program. N Engl / Med 2014;371:1803-12. doi:10.1056/ NEJMsa1405556

9 Sand-Jecklin K, Sherman J. A quantitative assessment of patient and nurse outcomes of bedside nursing report implementation. I Clin Nurs 2014;23:2854-63. doi:10.1111/jocn.12575

10 Mittal V. Family-centered rounds. Pediatr Clin North Am 2014:61:663-70. doi:10.1016/j.pcl.2014.04.003

11 Committee on Hospital Care. American Academy of Pediatrics. Family-centered care and the pediatrician's role. Pediatrics 2003;112:691-7. doi:10.1542/peds.112.3.691

12 Mittal V. Family-centered rounds: a decade of growth. Hosp Pediatr 2014;4:6-8. doi:10.1542/hpeds.2013-0100

13 Khan A, Baird J, Rogers JE, et al. Parent and provider experience and shared understanding after a family-centered nighttime communication intervention. Acad Pediatr 2017;17:389-402. doi:10.1016/j.acap.2017.01.012

14 Sanders LM, Shaw IS, Guez G, Baur C, Rudd R. Health literacy and child health promotion: implications for research, clinical care, and public policy. Pediatrics 2009;124(Suppl 3):S306-14 doi:10.1542/peds.2009-1162G

15 Brennan TA, Leape LL, Laird NM, et al. Incidence of adverse events and negligence in hospitalized patients. Results of the Harvard Medical Practice Study I. N Engl J Med 1991;324:370-6. doi:10.1056/NEIM199102073240604

16 Leape LL, Brennan TA, Laird N, et al. The nature of adverse events in hospitalized patients. Results of the Harvard Medical Practice Study II. N Engl I Med 1991;324:377-84. doi:10.1056/ NEJM199102073240605

17 Bates DW, Boyle DL, Vander Vliet MB, Schneider J, Leape L. Relationship between medication errors and adverse drug events. J Gen Intern Med 1995;10:199-205. doi:10.1007/BF02600255
18 Kaushal R, Bates DW, Landrigan C, et al. Medication errors and adverse drug events in pediatric inpatients. JAMA 2001;285:2114-20. doi:10.1001/jama.285.16.2114

19 Khan A, Coffey M, Litterer KP, et al, the Patient and Family Centered I-PASS Study Group. Families as partners in hospital error and adverse event surveillance. JAMA Pediatr 2017:171:372-81. doi:10.1001/jamapediatrics.2016.4812

20 Kincaid JP, Fishburne RP, Rogers RL, Chissom BS. Derivation of new readability formulas (automated readability index, fog count and flesch reading ease formula) for navy enlisted personnel. Institute for Simulation and Training, 1975. doi:10.21236/ADA006655.

21 Feudtner C, Christakis DA Connell FA. Pediatric deaths attributable to complex chronic conditions: a population-based study of Washington State, 1980-1997. Pediatrics 2000;106:205-9.

22 Feudtner C, Feinstein JA, Zhong W, Hall M, Dai D. Pediatric complex chronic conditions classification system version 2 : updated for ICD-10 and complex medical technology dependence and transplantation. BMC Pediatr 2014;14:199. doi:10.1186/1471-2431-14-199

23 Brick JM, Kalton G. Handling missing data in survey research. Stat Methods Med Res 1996;5:215-38. doi:10.1177/096228029600500302

24 Horton NJ, Lipsitz SR. Multiple imputation in practice: comparison of software packages for regression models with missing variables. Am Stat 2001;55:244-54. doi:10.1198/000313001317098266.

25 Rubin DB. Multiple Imputation for Nonresponse in Surveys. John Wiley \& Sons, 2008.

26 Harris PA, Taylor R, Thielke R, Payne J, Gonzalez N, Conde JG. Research electronic data capture (REDCap)--a metadata-driven methodology and workflow process for providing translational research informatics support. / Biomed Inform 2009;42:377-81. doi:10.1016/j.jbi.2008.08.010

27 COMMITTEE ON HOSPITAL CARE and INSTITUTE FOR PATIENT- AND FAMILY-CENTERED CARE. Patient- and family-centered care and the pediatrician's role. Pediatrics 2012;129:394-404. doi:10.1542/peds.2011-3084

28 Agency for Healthcare Research and Quality. Guide to patient and family engagement in hospital quality and safety. 2013. www.ahrq. gov/professionals/systems/hospital/engagingfamilies/guide.html (accessed 24 Oct 2018)

29 The Joint Commission. Advancing effective communication, cultural competence, and patient-and family-centered care: A roadmap for hospitals. The Joint Commission, 2010. www.jointcommission.org/ assets/1/6/ARoadmapforHospitalsfinalversion727.pdf (accessed 24 Oct 2018).

30 Small DC, Small RM. Patients first! Engaging the hearts and minds of nurses with a patient-centered practice model. Online J Issues Nurs 2011;16:2

31 Johnson B, Abraham M, Conway J, et al. Partnering with patients and families to design a patient- and family-centered health care system: recommendations and promising practices. Institute for FamilyCentered Care and the Institute for Healthcare Improvement, 2008.

32 Micalizzi DA, Dahlborg T, Zhu H. Partnering with parents and families to provide safer care: seeing and achieving safer care through the lens of patients and families. Curr Treat Options Pediatr 2015;1:298-308. doi:10.1007/s40746-015-0034-4.

33 Khan A, Furtak SL, Melvin P, Rogers JE, Schuster MA, Landrigan CP. Parent-reported errors and adverse events in hospitalized children. JAMA Pediatr 2016;170:e154608. doi:10.1001/ jamapediatrics.2015.4608

34 Dykes PC, Rozenblum R, Dalal A, et al. Prospective evaluation of a multifaceted intervention to improve outcomes in intensive care: the Promoting Respect and Ongoing Safety through Patient Engagement Communication and Technology study. Crit Care Med 2017:45:e806-13 doi:10.1097/CCM.0000000000002449

35 Hill C, Knafl KA, Santacroce SJ. Family-centered care from the perspective of parents of children cared for in a pediatric intensive care unit: an integrative review. J Pediatr Nurs 2017:S0882 5963(17)30531-6. doi:10.1016/j.pedn.2017.11.007

36 Bachnick S, Ausserhofer D, Baernholdt M, Simon M, Match RN study group. Patient-centered care, nurse work environment and implicit rationing of nursing care in Swiss acute care hospitals: A cross-sectional multi-center study. Int J Nurs Stud 2018;81:98-106. doi:10.1016/j.ijnurstu.2017.11.007

37 Skelton JR, Hobbs FD. Concordancing: use of language-based research in medical communication. Lancet 1999;353:108-11. doi:10.1016/S0140-6736(98)02469-6

38 Haynes AB, Weiser TG, Berry WR, et al, Safe Surgery Saves Lives Study Group. A surgical safety checklist to reduce morbidity and mortality in a global population. N Engl I Med 2009;360:491-9. doi:10.1056/NEJMsa0810119

39 Landrigan CP, Parry GJ, Bones CB, Hackbarth AD, Goldmann DA, Sharek PJ. Temporal trends in rates of patient harm resulting from medical care. N Engl J Med 2010;363:2124-34. doi:10.1056/NEJMsa1004404 
40 Landrigan C, Stockwell D, Toomey S, et al. Temporal Trends in Adverse Events Among Pediatric Inpatients. Plenary presentation at the Pediatric Academic Societies Annual Meeting; 2016; Baltimore, MD.

41 Stockwell DC, Landrigan CP, Toomey SL, et al, GAPPS Study Group. Adverse events in hospitalized pediatric patients. Pediatrics 2018;142:e20173360. doi:10.1542/peds.2017-3360

42 United States Census Bureau. 'B16001: Language spoken at home by ability to speak English for the population 5 years and over.' Data sets: Census, 2010; American Community Survey 5-Year Estimates, 2012-2016. American FactFinder (U.S. Census Bureau), http:// factfinder.census.gov (accessed 24 Oct 2018).

43 United States Census Bureau. 'Table 2: Educational Attainment of the Population 25 Years and Over, Both Sexes.' Data sets: Census, 2010; Current Population Survey, 2017 Annual Social and Economic Supplement. U.S. Census Bureau, www.census.gov (accessed 24 Oct 2018).

44 Gaba DM, Maxwell M, DeAnda A. Anesthetic mishaps: breaking the chain of accident evolution. Anesthesiology 1987;66:670-6. doi:10.1097/00000542-198705000-00013

45 Reason J. Understanding adverse events: human factors. Qual Health Care 1995;4:80-9. doi:10.1136/qshc.4.2.80
46 Cox ED, Jacobsohn GC, Rajamanickam VP, et al. A family-centered rounds checklist, family engagement, and patient safety: a randomized trial. Pediatrics 2017;139:e20161688. doi:10.1542/ peds.2016-1688

47 Neily J, Mills PD, Young-Xu Y, et al. Association between implementation of a medical team training program and surgical mortality. JAMA 2010;304:1693-700. doi:10.1001/ jama.2010.1506

48 Capella J Smith S, Philp A et al. Teamwork training improves the clinical care of trauma patients. J Surg Educ 2010;67:439-43. doi:10.1016/j.jsurg.2010.06.006

49 Pronovost P, Needham D, Berenholtz S, et al. An intervention to decrease catheter-related bloodstream infections in the ICU. N Engl Med 2006;355:2725-32. doi:10.1056/NEJMoa061115

50 Marsteller JA, Sexton JB, Hsu Y-J, et al. A multicenter, phased, cluster-randomized controlled trial to reduce central lineassociated bloodstream infections in intensive care units. Crit Care Med 2012;40:2933-9. doi:10.1097/CCM.0b013e31825fd4d8

Supplementary appendix: additional table and figures 